\title{
Involvement of Orang Asli Youth in Vocational Education and Training in Malaysia: Aspirations and Outcomes
}

\author{
Norwaliza Abdul Wahab ${ }^{1}$, Ridzuan Jaafar ${ }^{2}$, Sunarti $^{3}$ \\ ${ }^{1,2}$ Universiti Pendidikan Sultan Idris, Perak, Malaysia \\ ${ }^{3}$ Universitas PGRI Yogjakarta, Indonesia \\ norwaliza@fpm.upsi.edu.my ${ }^{1}$
}

DOI: https://doi.org/10.37134/ajatel.vol10.2.3.2020

Received: 20 April 2020; Accepted: 14 July 2020; Published: 20 July 2020

Cite this article (APA): Abdul Wahab, N., Jaafar, R., \& Sunarti, S. (2020). Involvement of Orang Asli Youth in Vocational Education and Training in Malaysia: Aspirations and Outcomes. Asian Journal of Assessment in Teaching and Learning, 10(2), 18-26. https://doi.org/10.37134/ajatel.vol10.2.3.2020

\begin{abstract}
Skilled human capital is highly important in economic development. This career aspiration is to create a skilled workforce in a country. A lack of Orang Asli involvement in vocational fields is worrisome for many parties, especially the government. Thus, this study aims to explore the participation and involvement of Orang Asli youths in Vocational Education and Training (VET). Qualitative research methods were used in this study to provide in-depth knowledge of the involvement of Orang Asli youths in VET. Ten Orang Asli youths from various ethnics groups, aged $17 \neg-18$, were selected as study participants. Data were obtained from semi-structured interviews and document analysis. From the analysed data, themes were pointed out and a triangulation technique was performed to determine the validity. The findings showed that awareness about VET among the Orang Asli youth is satisfactory. This paper also will discuss the involvement of Orang Asli youth in VET courses nationally and the unemployment among the Orang Asli youth because of their lack of skills and training required by employers. This paper also presents conclusions and recommendations to improve the participation of Orang Asli youth, especially in employment prospects and to enhance their socio-economic status among the communities for a brighter future.
\end{abstract}

Keywords: Orang Asli Youth, Orang Asli Employment, Skill and Training, Vocational Education and Training, Malaysia

\section{INTRODUCTION}

Education is a benchmark for future career success, which needs to be fought for; those who fight for it must be ready for challenges and obstacles (Castro, Andres \& Prestoza, 2018). Success is an aspiration and is part of efforts to create and maximise a skilled workforce. In Malaysia's 10th Malaysia Plan (2011-2015), human capital development of youth (including the minorities) is a priority (Mustapha et al., 2010). Meanwhile, stiff competition in the era of globalisation has made the Vocational Education and Training (VET) one of the main agendas of the country, enabling Malaysia to harness its human capital development, as stipulated in its Vision 2020 to gain the status of a developed country by 2020 (Wahab et al., 2014). To reach this goal, certain milestones need to be met. The increase in the number of skilled workers in specific critical fields is deemed necessary. To produce technical human resources, additional technical institutions and vocational training centres should be opened, especially for Orang Asli youth. Thus, professional education in Malaysia is facing new globalisation challenges that require it to adopt a new paradigm (Mohamed Rashid, 2002).

Orang Asli, or the aboriginal people Malaysia, experience immense stumbling blocks in every barometer of social and economic welfare. These disadvantages are experienced in government and private sectors. Orang Asli students' pass rates and qualifications remain well below those of other 
students. At present, access to VET is one option for most students, including the Orang Asli. A survey conducted to gauge Orang Asli participation in training and employment shows that the involvement of Orang Asli remains at the lowest level due to a lack of exposure on VET. Orang Asli communities in Malaysia are consistently labelled as a society lagging behind current mainstream development (Abdullah, 2006). The dropout rate of Orang Asli students is very high compared with that of students of other ethnic groups, especially among male students (Teese et al., 2000). The Department of Orang Asli Development (JAKOA) statistics reported that the dropout cases of Orang Asli students in education remain at approximately $30 \%$ per year in recent consecutive years (JAKOA, 2008). Students are the next generation who are expected to be agents of change, so education quality is essential (Martin, 2019)

According to JAKOA (2011), the school dropout statistics continue increasing even though education assistance has been provided accordingly. The Educational Planning and Research Division (EPRD) and the Ministry of Education (MOE) measured how many Orang Asli students completed their primary or secondary schooling. In 2011, approximately 30\% of Orang Asli students failed to complete their study. The dropouts occurred because they are less interested in academic subjects at school (Mustapha, 2009). Therefore, to reduce the poverty stigma among the Orang Asli people, VET should be provided to Orang Asli students so that they could receive appropriate skills training that suits their lives. Once they possess vocational skills, they can easily pursue employment or start businesses. However, not many Orang Asli students are pursuing vocational education offered in secondary schools. They may have difficulty entering vocational schools due to the remoteness of their villages from the schools or training institutions (Norwaliza et al., 2014).

The problems faced by Orang Asli children and youth, especially in education, are seriously considered by the Malaysian government. The government recognises that to develop the Orang Asli community, the priority is education (Ramle and Hood, 2007). Tikly and Barrett (2010) stated to guarantee indigenous people embracing educational quality levels, several aspects should be examined by the government, such as the foundations of the school and educational policies. Basir (2008) pointed out that the Orang Asli are mostly uninterested in the education provided by the government. ZainalAbidin (2004) showed that only 39\% of the Orang Asli received primary education, $11 \%$ received secondary education, and $2 \%$ received post-secondary education. The dropout rate among the Orang Asli is also high (Ramle and Hood, 2007). Furthermore, most Orang Asli adults do not know how to read, especially adults, and students are not motivated towards educations and careers. Unemployment is considered a severe problem in a country because it could bring economic and social problems. Thus, VET may be one solution in reducing the unemployment rate of a country (Rahayu et al., 2015).

Low awareness and achievement in education also affect the participation rate of Orang Asli people in the employment sector. Most Orang Asli people inherited traditional economic activities such as hunting and gathering of forest products and small-scale agriculture (Norwaliza et al., 2014). Only approximately $14 \%$ of Orang Asli people are engaged in other economic activities such as working in private companies and government departments (Lim, 1997). The government began a special programme to develop Orang Asli skills. Then, the government attempted to create a variety of programmes to improve the socio-economic status and education of Orang Asli communities. The programmes are conducted occasionally.

\section{RELATED LITERATURE REVIEW}

This chapter discusses and explores the related literature and studies, enabling us to develop a comprehensive review, perceptions and directions in this study. Particular information is found in references including journals, newspaper, books, magazines and websites.

\section{Orang Asli}

The Orang Asli are mainly grouped into three tribes, namely, Senoi, Semang (Negrito) and Proto Malay (Aboriginal Malay). They comprise 18 ethnic groups (Nicholas, 2000). The population of Orang Asli people in Malaysia is approximately 178,197, as per the latest figures (JAKOA, 2011). The Orang Asli 
community is a minority group that comprises $0.5 \%$ of Malaysia's total population. They live throughout the Peninsula except in the states of Perlis and Penang. Pahang has the largest community of Orang Asli people with 67,506 people (37.9\%), followed by Perak with 53,299 people (29.9\%) and Selangor with 17,587 people (9.9\%) (JAKOA, 2011).

Traditionally, the Orang Asli depend on forests and their corresponding resources to sustain their daily livelihood through hunting, fishing, hill paddy cultivation, forest production and vegetable cultivation. The Orang Asli poverty rate remains at a high level. Almost $80 \%$ of the Orang Asli population are estimated to earning below the poverty line (William-Hunts,1998). They practice a primitive way of life with an 'enough-for-life' economic orientation and are not involved in a market economy.

Orang Asli children have been categorised as a group jeopardised in the context of modernisation and hence face serious problems. Leaving the task of educating Orang Asli children to the JAKOA to improve their condition was futile. They were found to be unable to apply the knowledge acquired through formal education system in Malaysia due to the different settings of the environment (Wahab et al, 2020). The problem is that despite support from the government and other agencies, Orang Asli students remain underachieving and remain disengaged from school (Misnaton, Hamidah \& Marinah, 2016). Then, the government launched a policy that allocates special help to provide opportunities for equal rights, integrate them with the advanced section of the population and protect their traditional beliefs (Ministry of Education, 2006). Part of this initiative was conducted through the restructuring of the Orang Asli educational programme. The awareness of the Orang Asli people towards education is seen to be rising although it remains at a low level, as proven by an increasing number of school constructions in indigenous villages (Wan Afizi et al., 2014).

However, further training should be conducted for Orang Asli youths, especially for those who have left primary and secondary school, to equip them with necessary skills. Students of the Orang Asli community need to be offered assistance and encouragement to enrol in the institutions of higher learning and skills training centres such as polytechnics, community colleges and Pusat Giat MARA. In addition, the number of vocational courses in training centres managed by JAKOA needs to be extended to cover areas of forestry, construction, home-stay programme management, tailoring and handicraft. The existing training centres at Paya Bungor and Damansara Damai need to be upgraded to accommodate additional trainees. To overcome the shortage of teachers, the Ministry of Education has needed to employ teachers with low academic qualifications and temporary teachers, which is not an effective strategy to help the Orang Asli people in the long-term (Kamarulzaman \& Osman, 2008).

\section{Involvement of the Orang Asli in Vocational Education and Training}

Many local and foreign researchers have proven that the quality of life of indigenous peoples remains at a low level (Harun \& Idris, 2012). Meanwhile, the involvement and participant of Orang Asli students in VET remain shallow. In Australia, a survey found that students undertake training for many reasons. The main reasons that students undergo training are to obtain jobs $(42 \%)$ and to improve knowledge (43\%). Other causes include obtaining skills for community/voluntary work (19\%), helping in the community (20\%) or to improve confidence (24\%). In Malaysia, various attempts have been made to increase Orang Asli youth participation such as by increasing the number of vocational colleges and skills training institutes which aimed to provide individuals with specific skills to help them to obtain jobs. Technical institutions and skills centres were established to provide opportunities for students, especially Orang Asli students who lack the ability in the academic fields to acquire specific skills so that they can gain employment and remove themselves from poverty (Norwaliza et al., 2014).

Youths undertake VET to attain a qualification and for work purposes. The information obtained from the Division of Education in the State of Pahang in 2007 indicates that the number of Orang Asli students pursuing an education in VET is minimal at 11\% in 2006 and 7\% in 2008 (JAKOA, 2011). These data show that very few Orang Asli students are enrolled in vocational education. Mohd Salleh et al. (2009) found that the perception and awareness level of career planning among lowachieving students in Malaysia is deficient. Therefore, a student needs to know the area they will study in advance because this knowledge will help them choose and identify suitable areas and then follow the lessons successfully. This knowledge will also minimise the chance that the selected field strays from the interests and needs of the students. 
A total of 85,435 post-secondary school students were selected to pursue certificate and diploma courses at the Institute of Technical Education and Vocational Training (TEVT) and the Institute for Public Skills Training (IPST). This amount is an increase of $8.4 \%$ compared with 78,780 students in TEVT and IPST during the 2011/2012 school year (Ministry of Human Resources, 2012). The students include the physically challenged students (293 candidates), Orang Asli (59 candidates) and athletes (741 candidates). These students follow the programmes in 11 TEVT and IPST across the country. The ten most popular courses are Diploma in Hotel Management and Catering, Tourism Management, Finance and Banking, Accounting, Business Studies, Electrical Engineering, Automotive Technology, Management of Information Systems, Civil Engineering and Diploma in Secretarial Science. According to one of the study participants, Orang Asli youth lack the knowledge and awareness in identifying areas in vocational education. They do not know the existence of the training institutions such as community colleges, MARA and Giat Mara, which provide skill training courses to secondary school leavers.

\section{RESEARCH METHODOLOGY}

The study was conducted using a qualitative research design. The design of this study was selected to understand and to obtain a clear picture of the involvement of Orang Asli youth in VET. Ten Orang Asli youths from various ethnic groups and consisting of five males and five females aged 17-18 were involved in this interview. Each interview was approximately one hour and recorded with consent. According to Bowler and Weinraub (2018), adolescents aged 13-18 have the task of career development in the direction of education, for example, in choosing majors or career fields. The participants were selected using purposive sampling techniques. The selection of the research participants was based on the ability and willingness of the respondents themselves to provide the information needed to answer the research question (Creswell, 2013). All of them are currently taking courses at the two training centres of PBTC and DDTC. A set of protocol interviews was used during the semi-structured interview. The data obtained from the research participants were analysed. Demographic characteristics are shown in Table 1.

Table 1. Demographic characteristics of Orang Asli youth

\begin{tabular}{|c|c|c|c|c|c|}
\hline Code & Gender & Age & Ethnicity & Venue & Course \\
\hline MOA1 & Male & 17 & Semai & DDTC & Automotive \\
\hline MOA2 & Male & 17 & Jakun & DDTC & Automotive \\
\hline MOA3 & Male & 18 & Jakun & DDTC & Repairing \\
\hline MOA4 & Male & 18 & Semai & DDTC & Motorcycle \\
\hline MOA5 & Male & 17 & Semai & DDTC & Excavator \\
\hline FOA1 & Female & 17 & Jakun & PBTC & Tailoring \\
\hline FOA2 & Female & 18 & Semai & PBTC & Tailoring \\
\hline FOA3 & Female & 17 & Jakun & PBTC & Tailoring \\
\hline FOA4 & Female & 17 & Semai & PBTC & Fashion \\
\hline FOA5 & Female & 18 & Jakun & PBTC & Fashion \\
\hline
\end{tabular}

\section{FINDINGS AND DISCUSSIONS}

The study aimed to examine the involvement of the Orang Asli youths in VET from the interview and literature review from newspaper, magazines, journals and books. The findings for the Orang Asli youth involvement in VET can be summarised thematically into two categories: i) awareness of VET and skills programmes and ii) training and employment programmes. 


\section{Awareness of VET and Skills Programmes}

Interview data showed that the Orang Asli youth were aware of skills training programmes offered to Orang Asli youth from word-of-mouth. According to the research participants, the form of training that is given is with collaborative training centres, such as KEMAS, GIAT MARA and IKBN; private firms that have training centres as well as other training centres funded by the government. Two respondents stated the followings:

'I went to GIAT MARA, but some of my friends went to IKBN and KEMAS for training. I know about this training centre from my friends. We wanted to go because we were given an allowance by the government.'

(MOA1)

'I know about these courses from my friends. They invited us to join along.'

Orang Asli youth choose VET for work and to attain a qualification purpose. According to the research participants, policies are provided to low achievers among the Orang Asli youth in the form of vocational training and technology-based advanced vocational training centres. Institutions that provide such programmes have training from basic to advanced levels.

'Even though our qualifications are lower than others, we still have chances to enter this training centre because of our status as Orang Asli. This is a good opportunity.'

(MOA3)

According to one of the study participants, several types of skills programmes are available to Orang Asli communities to train them to improve their social mobility through employment that may lead them out of poverty.

'We can choose from several types of skills programmes, such as repairing motorcycles and cars and fixing electrical items such as air conditioners. I have liked repairing motorcycles since I was small. Now I can learn the proper way, earn some money and help my poor family.'

(MOA5)

Among the objectives of the programme is to help Orang Asli youth be skilled and later be employed. A collaborative programme also exists with JOB Malaysia and well-known Malaysian companies such as PERODUA and EON to recruit workforce from among the Orang Asli people. A respondent stated that:

'I am pursuing automotive technology. After finish my training, I hope I can work with PERODUA or EON.'

The Public Service Commission, which is a leading agency in appointing civil servants, also provides job quotas for the Orang Asli. One of the centres provides skills courses certified by the Malaysian Skills Certificate. This training centre is an accredited centre for Female Fashion and Clothing Levels I and II. This course is conducted for eight months. Participants who complete the course will be given a Malaysian Skills Certificate by the Department of Skill Development (DSD), Ministry of Human Resources. According to one of the participants,

'Each intake session consists of 50 students and this fashion course is about eight months.' 
The training centre offers courses such as automotive technology, motorcycle technology, repairing and painting of vehicles technology, excavator operation and manufacturing of female clothing. The purpose to provide opportunities to many target groups. Furthermore, it is expected to help increase family income quickly and independently to encourage the target groups to improve existing skills. The centre also enables them to join others in the job market. The training centre also offers courses for jobs such as electrician, hotel management and assistant in oil and gas. One of the research participants said

'After finishing the training, my friend said he could earn an income of approximately RM 3,000 a month.'

(MOA2)

According to a research participant, Orang Asli female youths need to complete and acquire a Level 1 certificate in tailoring from the National Vocational Training Council (MLVK) at the centre. The Skills Development Fund caters to these institutions and provides financial assistance to students.

'I took tailoring because I love sewing clothes, but I have to pass my Level 1 before I go to the next level. My dream is to open a tailoring shop one day near my village.'

(FOA1)

In the website, the specific requirements are as follows: the candidate must be Orang Asli according to Act 134, the Aboriginal Peoples Act 1974, and they must have interests in sewing and embroidery. They also should be mentally and physically healthy. The study participant stated that they also would be provided with incentives or allowance courses:

'We were given a place to stay and allowance. I am happy because I can do something that I like. At least I know I can earn some money now.'

(FOA2)

Technical institutions and skills centres were established to provide opportunities to Orang Asli youths who lack the ability in the academic field to acquire specific skills so that they can gain employment and remove themselves from poverty. Various attempts have been made to increase female Orang Asli youth participation in this country such as by increasing the number of vocational colleges and skills training institutes which aimed to provide individuals with particular skills to help them obtain jobs. The participation of Orang Asli students, especially the female Orang Asli youth, in the technical and vocational education remains low.

\section{Training and Employment Programme for Orang Asli Youths}

The majority of Orang Asli youth are either unemployed or self-employed (Ramlee et al., 2010). According to JAKOA (2016), the Skills Career and Training Programme (SCTP) is one of the government's initiatives with Orang Asli community in terms of improving their economic status and strengthening human capital. The effectiveness and success of SCTP will produce an Orang Asli community that can improve their financial status through careers. The respondents said the following:

'I am thinking to open a tailoring shop one day. I want to help my poor family.'

'We are poor. We do not have money to buy things that I want. I hope I can get a job soon after I finish this course.'

(FOA4)

At the same time, the competitive attitude among Orang Asli will be implemented through SCTP and the strengthening of human capital. This programme is the component breakdown of the Training and 
Education Programme in the 8th MP. This training is supposed to enhance the capabilities of the Orang Asli group so that they can obtain jobs or run service businesses that can deliver higher revenues and removing themselves and their families out of poverty.

Under the skills training component, assistance may be provided for participants to attend skill training in all areas in all sectors. Example courses include as tailoring, clerk booking and ticketing, food preparations, prime mover operator, cooking, food processing, computer repairs, motor mechanics, electrical, makeup and hairdressing. Additional Orang Asli staff are required to keep pace with Orang Asli involvement in VET (JAKOA, 2017). One of the study participants said

'I am so excited when my friend worked as a tourist guide after graduating from SCTP. I cannot wait to finish my training, so I can work too and earn money for my family and me.'

Most Orang Asli youths were tempted to join SCTP after seeing their relatives and friends succeed after completing the course. The phenomenon that continues to often arise is that in determining their career choice, high school students still usually follow the decisions of their friends, which are not necessarily the right decisions (Fadilla et al., 2020). According to JAKOA, thousands Orang Asli youths had benefitted from SCTP since its launch in 2011. A variety of choices is available for them, from industrial automation engineering, green-keeping, air-conditioner servicing, aesthetic services, baking, hair styling, tailoring and plumbing. The research participants stated that the lack of appropriate knowledge and qualifications are the factors that caused Orang Asli Youth to be unable to retain good jobs:

'Most of us did not know what to do after finishing secondary school. Moreover, our results were not good for going to university. I had applied for a few jobs but they said that I do not have skills or qualifications.'

(FOA4)

Therefore, students, especially Orang Asli pupils, need to know the opportunities to further their education in TVE in advance so that interested students are encouraged to continue their skills studies at a higher level. Career paths should be designed at the lower secondary level itself to enable students, especially Orang Asli students, to improve their understanding of their course of action immediately after completing their studies at a higher secondary school level. Opportunities to study at a higher level should also be simplified and multiplied. More training should be conducted for Orang Asli youths to equip them with necessary skills. In determining career choices, students are suspected to be more likely to follow group decisions to gain social acceptance because peer groups play a significant role in meeting the needs of adolescents socially and emotionally. Individuals who identify themselves with groups cause the individual's dependence on their parents to decline (Padmomartono, 2014). Orang Asli youths need to be offered assistance and encouragement to enrol in institutions of higher learning and skills training centres like community colleges, Pusat Giat MARA and polytechnics (Kamarulzaman and Osman, 2008).

Career opportunities were also considered influential factors for students selecting vocational education (Asnul Dahar \& Zulkifli, 2010). Thus, significant opportunities for Orang Asli students to choose the training courses of their interest should be provided, enabling them to obtain improved employment opportunities. Recently, indigenous peoples across the country are Technical and Vocational Education and Training (TVET) programmes free of charge at all skilled institutions under the Ministry of Human Resources. The move was a government commitment to the Orang Asli community's high populations in extreme poverty by giving academic and skill training education. The special provision was needed to encourage more Orang Asli to take up TVET. These developments also motivated this paper in discussing the involvement of Orang Asli youths in vocational and educational training in Malaysia. 


\section{SUMMARY AND RECOMMENDATIONS}

The involvement of communities making decisions about what training is needed, when and where, for whom, and embedding it in community business is important. Therefore, Orang Asli students need to gain sufficient knowledge about VET offered in skills training institutions throughout the country. When they have extensive experience, awareness can be created among Orang Asli students about the importance of vocational education in transforming their lives and improving their futures. Therefore, Orang Asli students in primary and secondary schools should be provided sufficient information while still in school to enable them to select their preferred choices of vocational programmes later in life. Technical and vocational subjects should be introduced for Orang Asli students starting in primary school. Subjects offered must fit their needs and interests, such as sports, music, agriculture and handicrafts. Ideally, teachers who teach technical and vocational education be Orang Asli teachers themselves because they possess an in-depth understanding of the needs, cultural backgrounds and language of their people.

VET must be able to develop students' own identities, cultures and histories to provide appropriate spaces in which students can acquire skills for employment, community development and self-determination. Education and training is a social activity, and as such must be discussed between students and teachers to ensure that the structures, environment and content are congruent with the Orang Asli backgrounds and culture. Aboriginal-specific training materials are essential to ensure that training is well-accepted, relevant and useful to Orang Asli youths. Different means have to be provided to ensure that Orang Asli people are heard in all aspects of VET, from programme development to funding and delivery to evaluation. Furthermore, Orang Asli role models, leaders and mentor representatives in decision-making bodies should be identified and supported. Finally, the issue is not one of involvement in VET but of retention, completion and re-enrolment in higher levels and industryrelevant courses which will most likely lead to employment and economic outcomes. Public and the non-government agencies should also play roles in exposing the youth to outside agencies. The public should not have negative stereotypical perceptions towards Orang Asli youth, especially in giving career or job opportunities and advising on technical and generic skills.

\section{REFERENCES}

Asnul Dahar, M. \& Zulkifli, S. (2010). Faktor-Faktor yang mempengaruhi pemilihan pelajar mengikuti mata pelajaran akademik di sekolah menengah akademik harian di daerah Hulu Langat, Selangor. Retrieved from http://eprints.utm.my/10820/

Azizah, A. H. (2008). Left behind? The policies are in place, but indigenous students still face problems. The Star, 28 February 2008.

Basir, Z. (2008). The Indigenous Educations. Berita Harian. Centre, Y. E. (2006). Increasing vocational learning opportunities for Indigenous students in juvenile detention: A national research project. Dusseldorf Skills Forum, website www. dsf. org

Bowler, G., \& Weinraub, M. (2018). The SAGE encyclopedia of lifespan human development. https://doi.org/10.4135/9781506307633

Castro, M. R. D., Andres, P. D., \& Prestoza, M. J. R. (2018). The Teaching Techniques and Strategies Used by the Dressmaking Teachers Perceive by the Dressmaking Students. Asian Journal of Assessment in Teaching and Learning, 8, 48-56. Retrieved from http://ejournal.upsi.edu.my/index.php/AJATeL/article/view/1988

Department of Orang Asli Development. (2017). Orang Asli Was Given Skills Training and Career Program $(S C T P)$. Capaian http://www.jakoa.gov.my/en/tugasmulia-jasakepadaorangasli-jakoamalaysiaorangasli-di-beri-program-latihan-kemahiran-dan-kerjaya-plkkmatla/

Harun, M. F. M. \& Idris, N. A. H. (2012). The quality of life of Malaysian aborigines: measured with a weighted quality of life index for Orang Asli. Akademika, 82(1), 75-81.

JAKOA. (2017). Training and Employment Program. Capaian http://www.jakoa.gov.my/en/orang-asli/programminda-latihan/program-latihan-kemahiran-kerjaya-plkk/

JAKOA. (2008). Pembangunan Orang Asli-Cabaran dan Kejayaan. Seminar Mengenai Pembangunan Masyarakat Orang Asli: Cabaran dan Kejayaan. Sempena Hari Orang Asli Sedunia. Pusat Pengajian Peribumi Malaysia.Universiti Malaya. Tidak Diterbitkan. 
JAKOA. (2011). Strategic Planning of The Indigenous 2011-2015. Kuala Lumpur: The Indigenous of Development Department in Malaysia.

Kamarulzaman, K and Osman, J. (2008). Educational Policy and Opportunities of Orang Asli: A Study on Indigenous People in Malaysia, The Journal of Human Resource and Adult Learning, 4(1), pp88-97

Lim Hwei Mian. (1997). Nutritional Status and Reproductive Health of Orang Asli Women. BSc. (Human Development) Project. Faculty of Human Ecology. Universiti Putra Malaysia. Serdang.

Martin, M. (2019). Implementation and usefulness of outcomes-based instruction among college of education students. Asian Journal of Assessment in Teaching and Learning, 9(2), 18-28. Retrieved from http://ejournal.upsi.edu.my/index.php/AJATeL/article/view/2790

Misnaton Rabahi, Hamidah Yusof, Marinah Awang. (2016). Leading learning among the indigenous orang Asli students: Setting the scene. GEOGRAFIA OnlineTM Malaysia Journal of Society and Space, 12 (13), pp. $120-134$

Mohd Rashid, N. B. (2002). Technical vocational education, Polytechnics and Community Colleges. The Malaysian Educational Odyssey. Selangor: Oxford Fajar Sdn Bhd.

Mohd Salleh, A., Mustapha, R, and Mahmud, Z. (2009). Career planning for marginalised children. Education for diverse learners. Serdang: Universiti Putra Malaysia Press, p. 117-134.

Nicholas, C. (2000). The Orang Asli and the Contest for Resources: Orang Asli Politics, Development and Identity in Peninsular Malaysia. International Work Group on Indigenous Affairs, Copenhagen/Center for Orang Asli Concerns. Subang Jaya.

Norwaliza, A.W, Ramlee, M, Abdul Razaq, A and Zalizan, M.J. (2014). Vocational Education and Skills Training for Indigenous Community in Malaysia. Journal of Education and Practise, 5(11), 179-184

Padmomartono, S. (2014). Konseling remaja. Yogyakarta: Ombak

Fadilla, P.F., Abdullah, S.M, Wu, M. (2020). Does conformity occur during students' decision making for their careers? Asian Journal of Assessment in Teaching and Learning, 10(1)1, p.p 1-9.

Rahayu, A.B, Ramlee, M, Ahmad, M.S, Mohamed Nor Azhari, A and Tee Tze Kiong. (2015). Identification of Vocational Talent among Students: Theoretical Perspectives. Journal of Asian Vocational Education and Training, Vol. 8, pp. 45-58.

Ramle, A. (2006). Potential Assessment Report of The Orang Asli Terengganu Education Students. Not published.

Ramle, A and Hood, S. (2007). Tracking Study Report on Indigenous Students. Not published.

Ramlee Mustapha et al. (2009). Career Development of The Indigenous Youth. The Indigenous Community: Perspectives in Education and Culture. Penerbit UKM: Bangi.

Ramlee Mustapha, Mustaffa Omarb, Syed Najmuddin Syed Hassan, Ruhizan Mohd Yasin, Norani Mohd Salleh. (2010). Human Capital Development of Orang Asli Youth: Supportive and Suppressive Factors. Procedia Social and Behavioral Sciences, 7(C), 592-600

Teese, R, Polesel, J, O'Brien, K, Jones, B, Davies, M, Walstab, A \&Maughan, M. (2000). Early school leaving: a review of the literature. Australian National Training Authority. Brisbane

Tikly, L., A.M. Barrett. (2010). Social justice, Capabilities and the quality of education in low-income countries. International Journal of Educational Development. DOI: 10.1016/j.ijedudev.2010.06.001

The Economic Planning Unit. (2006). The Ninth Malaysian Plan 2006 - 2010, Putrajaya: Department of Prime MinisterWan Afizi Wan Hanafi, Shaharuddin Ahmad \& Noraziah Ali. 2014. Faktor budaya dan persekitaran dalam prestasi pendidikan anak Orang Asli Malaysia: Kajian kes di Kelantan. GEOGRAFIA OnlineTM Malaysian Journal of Society and Space, 5(5), 107-122

Wahab, N.A., Goh, P.S, Ong, E.T., Ibrahim, M.H \& Affandi, H.M. (2020). Construction of the forest school framework based on indigenous knowledge in Malaysia. Cakrawala Pendidikan, 39(2), p. 270-278. https://doi:10.21831/cp.v39i2.29316

William-Hunt, A. (1998). The Indigenous and Development Challenges. Bil.8, Department of Anthropology \&Sosiology, Bangi: Universiti Kebangsaan Malaysia.

Zainal Abidin, A. (2004). Department of The Indigenous Affairs: Role in Research. Seminar Sehari Tradisi Lisan Masyarakat Orang Asli.8 Sept. 2004. Universiti Kebangsaan Malaysia. Bangi. 